\title{
A new technique to improve $A C$ coil contactor switching in presence of voltage sags
}

\author{
Sonali Mayuresh Akolkar ${ }^{1}$, Bansidhar Eknath Kushare ${ }^{2}$ \\ ${ }^{1}$ Electrical Engg. Dept.,of K.K. Wagh I. E. E. \& R, Nagpur University, Nashik (Maharashtra), India \\ ${ }^{2}$ Electrical Engg. Dept., K. K. Wagh I. E. E. \& R, Marathwada University and University Nashik (Maharashtra), India
}

\section{Email address:}

akolkar_sonali@yahoo.co.in(S. M. Akolkar)

\section{To cite this article:}

Sonali Mayuresh Akolkar, Bansidhar Eknath Kushare. A New Technique to Improve AC Coil Contactor Switching in Presence of Voltage Sags. Journal of Electrical and Electronic Engineering. Vol. 1, No. 4, 2013, pp. 79-84. doi: 10.11648/j.jeee.20130104.13

\begin{abstract}
Total complaints related to voltage sags are about $80 \%$ of all the complaints due to power quality transients. AC Contactors are designed to disconnect the load or circuit they control when the main power supply is intentionally interrupted. The sensitivity of AC coil contactors to the applied voltage is thus a potentially weak link in industrial processes. This paper shows the test results obtained from extensive laboratory testing carried out on AC coil contactors to voltage sags with variation in value of point on wave angle of voltage sags. The testing was carried out considering various sag magnitudes, durations and point on wave initiation angles of supply voltage waveform. Voltage tolerance curves for AC contactor have been plotted which gives an idea about equipment malfunction for different sag events. This kind of typical equipment sensitivity data might be useful for the future sag assessment methods. Line to line transformer is also suggested for improving AC coil contactor behavior during voltage sags
\end{abstract}

Keywords: AC Contactor, Voltage Sag, Equipment Sensitivity, Voltage Tolerance Curve

\section{Introduction}

Customer complaints related to voltage sags represent approximately $80 \%$ of all the complaints due to power quality transients [7]. Voltage sag is caused by a fault in the utility system, a fault within the customers' facility or a large increase of the load current, like in case of starting a motor or transformer energizing. Typical faults in a power system are single-phase or multiple-phase short circuits, which leads to high currents. The high current results in a voltage drop over the network impedance.

According to the Standard IEEE 1346 (IEEE Std 1346, 1998), Voltage sag is " a decrease in RMS voltage or current at the power frequency for durations of 0.5 cycles to 1 minute".

\subsection{Voltage Sag Magnitude}

To give a numerical value to sag, the recommended usage is sag to "X \%", which means that the line voltage is reduced down to $\mathrm{X} \%$ of the normal value. Voltage sag, also known as voltage 'dip' is an electromagnetic disturbance, the level of which is mainly determined by the magnitude and duration. Magnitude of voltage sag is the value of residual voltage during the event.
A common practice of characterizing sag is through remaining voltage during sag, which is given as the percentage of nominal voltage. Thus, a $70 \%$ sag in $120 \mathrm{~V}$ system means that the voltage is dropped to $70 \%(84 \mathrm{~V})$. Thus $70 \%$ sag means remaining voltage is $70 \%$ of nominal voltage. "Thus a $50 \%$ sag in a $120 \mathrm{~V}_{\mathrm{RMS}}$ mains voltage results in a voltage drop of $60 \mathrm{~V}_{\mathrm{RMS}}$. Figure 1 presents this concept taking into consideration a four cycle sag duration under normalized amplitude voltage "This method of characterizing sag magnitude is recommended in number of IEEE standards like: 493-1998, 1159-1995, and 13461998.

\subsection{Voltage Sag Duration}

A drop in voltage during sag can be due to a short circuit in the system. In this case, the moment the short circuit fault is cleared by the protection system, the voltage can return to its original value. The duration of sag is mainly determined by the fault clearing time but may be longer than the fault clearing time. The main protection implemented in distribution system is the over current protection which requires some time grading for the time 
of operation of successive over current relays in the system to act as back up protection if primary protection fails. This increases fault clearing time of the related circuit breaker. The sag duration will be longer if the sag originates at lower voltage level.

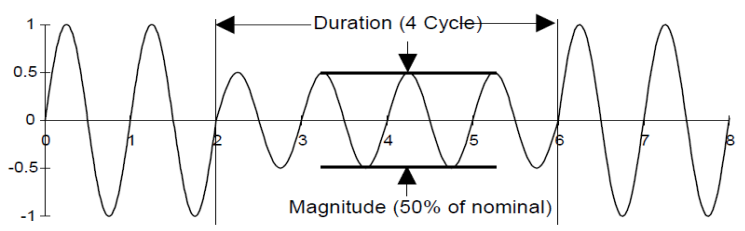

Fig. 1. Waveform showing voltage sag with $50 \%$ sag for four cycles

\subsection{Point on Wave of Voltage Sag}

Point-on-wave of sag initiation is the phase angle of the fundamental voltage wave at which, the voltage sag starts when fault occurs in the system. This characteristic of voltage sag is useful in studying equipment malfunction during voltage sags. Some of the waveforms for point-onwave of voltage sag obtained in MATLAB programming are depicted in fig2.

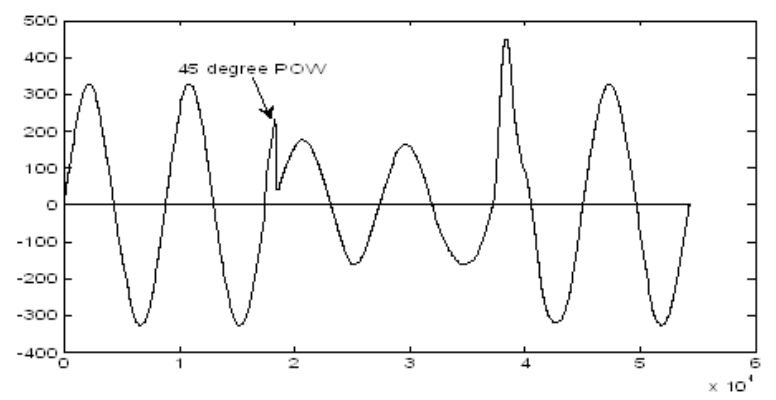

(a)Waveform with $45^{\circ}$ Point on Wave initiation

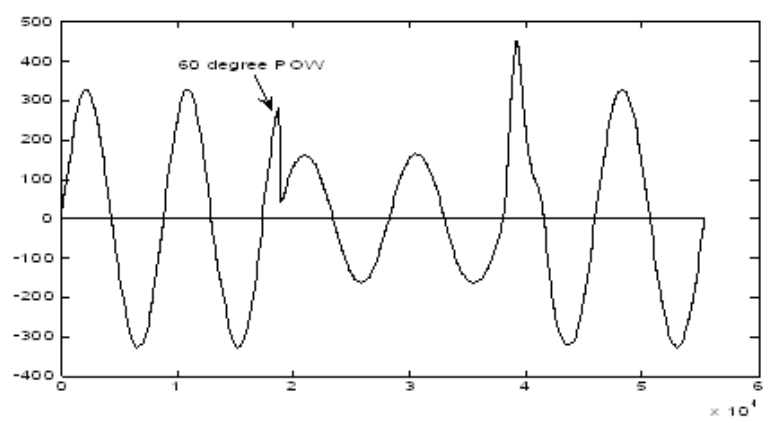

(b) Waveform with $60^{\circ}$ Point on Wave initiations

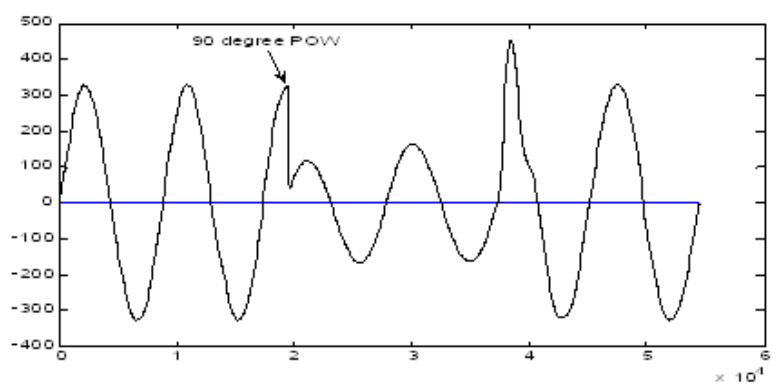

(c) Waveform with $90^{\circ}$ Point on Wave initiations.

Fig2. Generated waveforms for different point on wave values.
From the review of previously published research literature related to sensitivity analysis of ac coil contactor and power supplies, it is observed that rare work is published regarding mitigation technique for enhancement of AC coil contactor behavior during voltage sags.

\subsection{Behavior of AC Coil Contactors to Voltage Sags}

AC coil contactors are used as electromechanical AC switches in several different kinds of systems. They are used for powering and process control. Despite a simple design they are often quite sensitive to voltage sags. Contactors, independently of the load connected to it, get disconnected because of a voltage sag in the supply feeding the contactor coil. The disconnection may lead to an uncontrolled situation and a shutdown of the system or the sub-process. The coil of contactor provides the force which offset the spring tension and ultimately causes electrical contacts to engage. When the current is switched off in the coil, the return spring pushes back the moving electro magnet which opens the contact so the contactor comes back to its normal (Off) state. During voltage sags, if coil magnetic force is less than the return spring force, contactor drops out immediately.

\subsection{Developed MATLAB Program to Calculate AC Coil Contactor Coil Magnetic Force}

A MATLAB program is developed for calculation of coil magnetic force against fixed value of spring force in shaded pole AC contactor. The distribution of flux in shaded portion is shown in fig. 3 .

The magnetic force for shaded pole AC coil contactor can be expressed by:

$$
\left[1 /\left(2 * \mu_{0} * A_{11}\right)\left[\Phi_{11}^{2} * \cos ^{2}(w t+\beta)\right]+1 /\left(2 * \mu_{0} * A_{3}\right)\left[\Phi_{8}^{2} \cos ^{2} *(w t-x)\right]\right.
$$

Where, 'Au' and 'As' is the cross sectional area of un shaded and shaded portion of the AC contactor core respectively. Similarly, ' $\Phi$ s' and ' $\Phi \mathrm{u}$ ' are shaded and un shaded flux respectively. ' $\alpha$ ' and ' $\beta$ ' are the angles of phase shift for shaded and un shaded part of core respectively. The other notations have usual meanings.

The input parameters to the program which are actually measured parameters are as follows:

\section{Spring Force-3.964 N}

No. of turns of contactor coil-2220

Resistance of coil-101.3 $\Omega$

Rated Coil current- $0.15 \mathrm{~A}$

Length of magnetic path- $0.231 \mathrm{~m}$

Area of un shaded portion- $0.00002609 \mathrm{~m}^{2}$.

Area of shaded portion- $0.00007013 \mathrm{~m}^{2}$ 


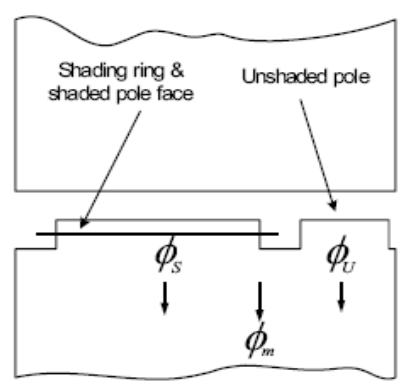

Fig: 3. Distribution of coil flux due to shading rings.

The criterion for $\mathrm{AC}$ contactor malfunction is that if coil magnetic force is less than spring force during a voltage sag event, then contactor mal operates.

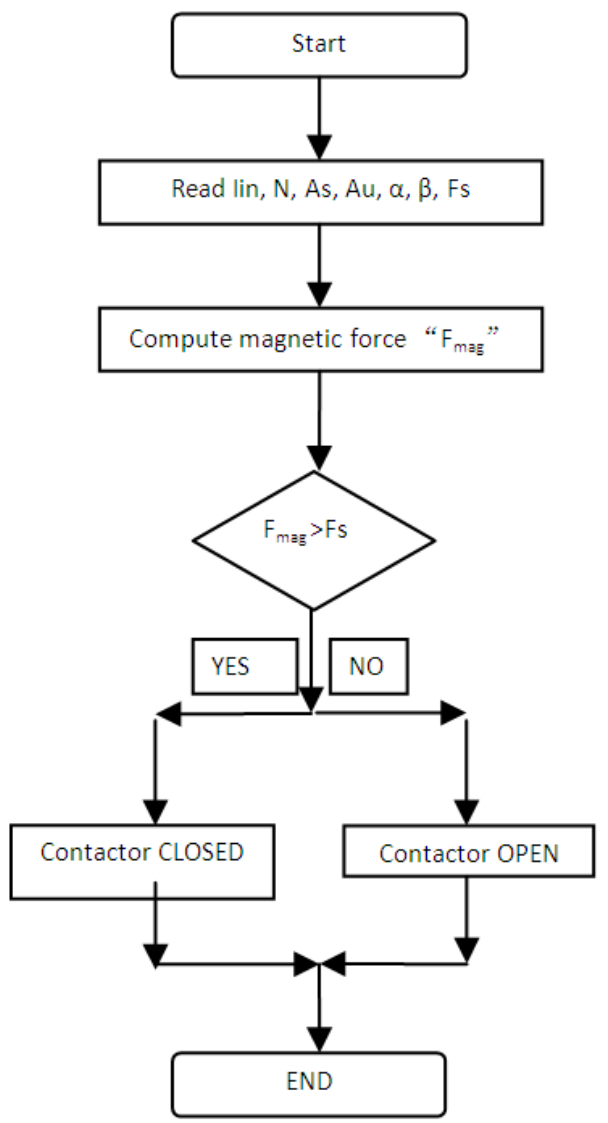

Fig 4. Flowchart to determine tripping of AC contactor against particular voltage sag.

\section{Experimental Setup}

Figure 5 shows experimental set up for evaluation of equipment sensitivity to voltage sags. The experimental setup is composed of a voltage sag generator, variable AC voltage transformers, a power supply and SSRs (solid state relays). A solid-state relay is an ON-OFF control electronic switching device in which a small control signal controls a larger load current or voltage. The sag generator has been designed to provide a wide variety of sags, with varying magnitudes, durations, and adjustable point-on-waves of sag initiation. The propagation delay is provided in time \& duration control circuit for generating different point on wave initiation angles of voltage sag.

The output of either of the two sources (one for normal supply voltage and another for sagged voltage) is fed to EUT (equipment under test) via solid state relays used for source selection. The output of variable ac transformer related to sagged supply decides the magnitude of voltage sag. The sag duration is set by time and duration control circuit.

Testing is carried in electrical engineering department laboratory of K.K.W.I.E.E. \&R., Nashik, (Maharashtra).

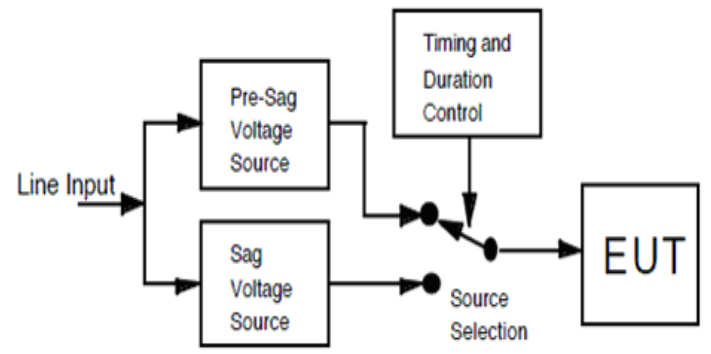

Fig 5. Test set up for evaluation of equipment sensitivity to voltage sags according to IEEE 1346.

\subsection{Standard Testing Procedure}

Tests are carried out according to international standard IEC 61000-4-11 which defines methods of immunity tests and range of low voltage equipment for testing. Current standards related to testing of equipment sensitivity to voltage sags suggest that testing is always related to simple rectangular voltage sags. There are no suggestions related to testing of equipment to nonrectangular voltage sags (for example two stage voltage sags) or voltage sags like those caused by the starting of large motors. Voltage waveforms used in test should be ideal sine waves at nominal frequency.

\subsection{Testing of AC Coil Contactor to Voltage Sags}

The AC coil contactors under consideration are: $24 \mathrm{~V}$, $110 \mathrm{~V}$ and $220 \mathrm{~V} 50 \mathrm{~Hz}$ with shaded pole structure which are tested without any load connected to their main electrical contacts. During testing, the nominal voltage was applied to coil of contactor before and after the voltage sag. The contactor was positioned as per manufacturer's recommendation so that the effect of gravity on the disengagement of the contactor is consistent throughout the tests.

Coil voltage, coil current and coil magnetic force are not measured during laboratory testing and only indication whether contactor in 'engaged' or 'dis-engaged', is observed using a 40W incandescent lamp in series with contactor power contacts.

1. The main electrical contacts of the contactor are engaged by applying nominal voltage to the ac coil of the contactor.

2. Voltage sag of different magnitudes starting from $10 \%$ voltage up to $90 \%$ was applied in steps of $5 \%$ of nominal voltage. For each sag magnitude, sag duration before which contactor disengages is identified. The sag duration 
required before disengagement is ascertained by ten repeated measurement for each sag magnitude at defined point on wave initiation.

3. After each disengagement, a minimum of one minute recovery time was allowed before the next voltage sag is applied. The duration of voltage sag during testing was selected between $10 \mathrm{~ms}$ to $500 \mathrm{~ms}$ and point on wave values were increased from $15^{\circ}$ to $90^{\circ}$ in steps of $15^{\circ}$. After $90^{\circ}$, values of point-on-wave of sag initiation angles are repeated and hence need not be considered.

\subsection{Test Results for AC Coil Contactor Sensitivity to Voltage Sags}

The result of the laboratory testing related to different AC coil contactors consisting of $24 \mathrm{~V} \mathrm{~L} \& \mathrm{~T}$ make (type A), $110 \mathrm{~V}$ Siemens make (type B) and 220V Compton Greaves make (type $C$ ) indicate that contactor sensitivity to voltage sags is affected by point on wave initiation angle in addition to sag magnitude and duration. As the point on wave angle approaches to $90^{\circ}$, instantaneous value of coil current approaches to minimum value because contactor coil is highly inductive in nature and as such coil current lags behind the coil voltage near to $90^{\circ}$. The angle may change depending upon the value of resistance of coil ' $R$ ' because coil angle is given as $\tan ^{-1}(L / R)$ where ' $\mathrm{L}$ ' is the self inductance of contactor coil. It is also observed that $\mathrm{AC}$ contactor sensitivity is different for different makes of contactor (L\&T, Siemens and CG make). Their behavior to voltage sags is very complex and difficult to predict in a linear way on common platforms. The obtained results are depicted in fig 6 and 7 respectively.

The area under the graph is area of mal-operation. i.e. a point on graph related to $40 \%$ sag for $20 \mathrm{~ms}$ reveals that $\mathrm{AC}$ contactor under study will dis-engage if either sag magnitude or duration is reduced further. This point may be treated as the threshold point for AC contactor under study.

Fig. 7 represents the results for only particular make of $\mathrm{AC}$ contactor considering similar values of sag magnitudes $\&$ durations for different set of readings but varying the value of point-on-wave of sag initiation each type. Similar plot can be obtained for other makes of AC contactors as well.

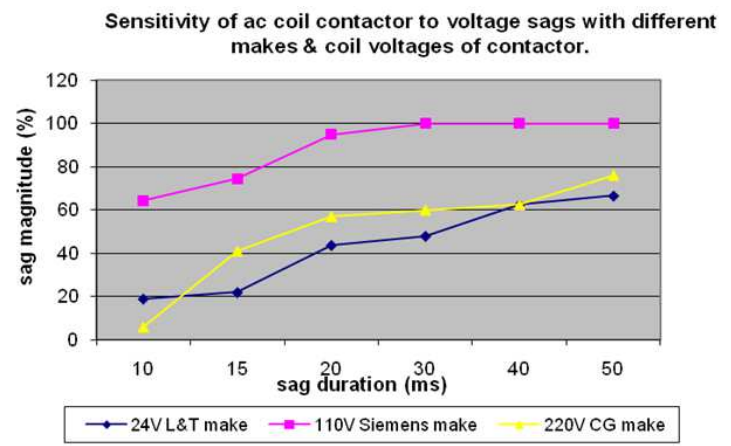

Fig 6. Voltage tolerance curves for AC coil contactors of different makes \& coil voltages.

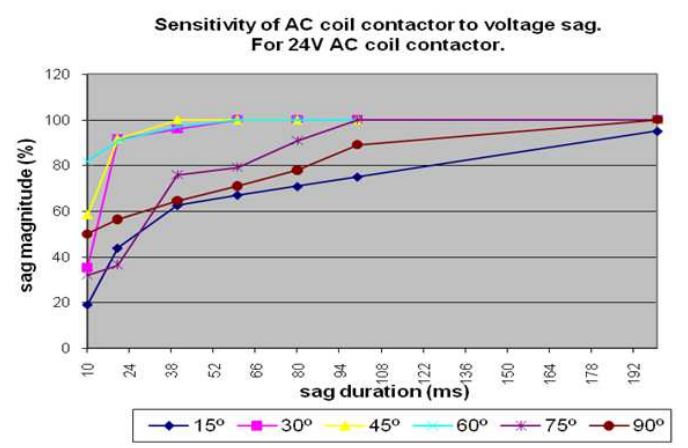

Fig: 7. Voltage tolerance curves for $24 V$ AC coil contactor with different point on wave values.

\subsection{Suggested Compensating Device for Enhancement of AC Coil Contactor Immunity to Voltage Sags}

In referred published research work, power supply is suggested as a ride through device for enhancement of $\mathrm{AC}$ contactor sensitivity to voltage sags [4]. Capacitor has also been suggested as a cost effective solution for improving contactor immunity to voltage sags [7]. In this project work, another cost effective solution for enhancement of AC coil contactor immunity to voltage sag has been worked out. A line-to-line connected transformer is a device having $415 \mathrm{~V}$ phase to phase primary voltage, one of the two phases being the coil phase itself and secondary winding providing rated contactor coil voltage.

The AC coil contactor used for this work is having shaded pole structure with $220 \mathrm{~V}$ AC coil and line-to-line line connected transformer rated as $415 \mathrm{~V} / 220 \mathrm{~V}, 50 \mathrm{~Hz}$. Variety of sags having different magnitudes, durations and at different point on wave angles ranging from $15^{\circ}$ to $90^{\circ}$ were applied to contactor coil before and after application of line-to-line connected transformer. The results obtained without and with application of suggested compensating device are depicted in fig: 8 .

\section{Contactor ride through enhancement in case of $\mathbf{9 0} \mathrm{deg}$.}

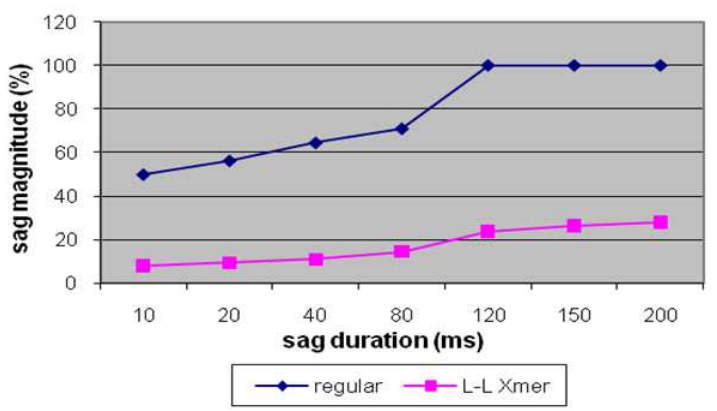

Fig 8. Superimposition of curves for $110 \mathrm{~V}$ AC coil contactor without \& with suggested compensating device.

\subsection{Suggested Design Modifications in AC Contactor for Enhancement of AC Contactor immunity against Voltage Sags}

The coil magnetic force depends on the shaded area and shaded flux which in turn depends on the length of core. (Refer sec. 1.5). Hence effect of variation of following coil parameters on contactor sensitivity have been studied 
through the developed MATLAB program by varying any one parameter in steps at a time and keeping the other parameters unchanged. (Refer fig. 4 for flow chart).

I. Length of core

II. Shaded area of core

A 3 phase, 6A, 415V, $50 \mathrm{~Hz}$ Bhartiya Cutler Hammer make AC coil contactor with $110 \mathrm{~V}$ rated coil voltage is considered for running the program in MATLAB and all the parameters required for mathematical modeling of contactor have been measured and used. The shaded and un shaded flux will depend upon the amount of current in contactor coil which in turn depends upon the sag intensity. The details of measurement have been given below:

Table 1.1. Measurements related to ac contactor model.

\begin{tabular}{lll}
\hline Sr. No. & Model Parameter & Measured value \\
\hline 1. & Spring Force & $3.964 \mathrm{~N}$ \\
2. & No. of turns & 2220 \\
3. & Resistance of coil & $101.3 \Omega$ \\
4. & Rated Coil current & $0.15 \mathrm{~A}$ \\
5. & Length of magnetic path & $0.231 \mathrm{~m}$ \\
6. & Area of un shaded portion & $0.00002609 \mathrm{~m}^{2}$ \\
7. & Area of shaded portion & $0.00007013 \mathrm{~m}^{2}$ \\
\hline
\end{tabular}

Table 1.2. Effect of change in magnetic length of core on coil magnetic force

\begin{tabular}{lll}
\hline Sr. No. & Core length $(\mathbf{m m})$ & $\mathbf{F}_{\text {mag }}$ (Newton) \\
\hline 1 & 0.135 & 3.45 \\
2 & 0.14 & 3.356 \\
3 & 0.145 & 3.129 \\
4 & 0.15 & 2.924 \\
\hline
\end{tabular}

Table 1.3. Effect of change in shaded area of core on coil magnetic force

\begin{tabular}{lll}
\hline Sr. No. & $\begin{array}{l}\text { Shaded area of core } \\
\text { (sq. } \mathbf{~ m . )}\end{array}$ & $\begin{array}{l}\mathbf{F}_{\text {mag }} \\
\text { (Newton) }\end{array}$ \\
\hline 1 & 0.000075 & 2.745 \\
2 & 0.00008 & 2.925 \\
3 & 0.000085 & 3.105 \\
4 & 0.000095 & 3.465 \\
\hline
\end{tabular}

\section{Conclusions}

The following conclusions can be drawn from the test results and simulation work:

1. AC coil contactors are sensitive to point on wave initiation angles in addition to sag magnitude and duration. The AC contactor under consideration is sensitive to sags with less than 10 to 20 milliseconds.

2. Sensitivity of AC coil contactor to voltage sags changes with different makes \& coil voltage ratings.

3. It is observed through laboratory testing that using line-to-line connected transformer, ac contactor can ride through particular sags because in such case, the coil gets sufficient voltage from the un sagged phase connected to its primary winding.

4. From performed laboratory tests, the $\mathrm{AC}$ coil contactor model under consideration is able to overcome the sag down to $25.5 \%$ for 200 milliseconds using line-to-line connected transformer. Hence line-to-line connected transformer could be a cost effective solution to increase contactor immunity to voltage sags to some extent.

5. The AC contactor immunity to voltage sags can be improved to some extent by considering design modifications in magnetic circuit as explained in sec. 2.5. From Table 1.2, it is clear that as the core length is increased, the contactor is more sensitive to similar type of sag. In contrast, as the shaded area of core is increased, contactor immunity to similar type of sag is increased.

6. The immunity of AC coil contactor may also be improved to some extent by using a spring with lesser value of spring force than the existing one without affecting the normal working of contactor (normal supply condition without sag event).

\section{Acknowledgment}

The author is thankful to the staff of electrical engineering department of K.K.W.I.E.E.\& R., Nasik, for their contributions, time to time encouragement and guidance in the project work and also to Principal and Management of K.K.W.I.E.E. \& R, for providing facilities to present this work.

\section{References}

[1] J. Pedra, F. Corcoles, and L. Sainz, "Study of AC contactors during voltage sags," Int. Conference on Harmonics and Quality of Power, IEEE 2002.

[2] Hasmaini Mohammad, Khalid Mohamed, Malaysia, "Evaluation on sensitivity of AC contactor during voltage sag" 0-7803-8560- 8/04/\$20.00@2004 IEEE.

[3] Juan C. Gomez Morcos, Rio Cuarto, USA, "Contactor immunity related to voltage sags", 19th International Conference on Electricity Distribution Vienna, 21-24 May 2007.

[4] P. Andra, G. Navarro, J.I. Perat, "A new power supply system for AC contactor ride-through", 9th International conference on electrical power quality and utility-October 2007.

[5] P. Pohjanheimo and M. Lehtonen, "Equipment Sensitivity to Voltage Sags-Test Results for Contactors, PCs and Gas Discharge Lamps", 2002 IEEE

[6] Bansidhar E. Kushare, Ashok A. Ghatol, "Investigation of cost effective method to improve voltage sag ride through capability of AC coil contactors", International Conference (ICTES 2007), Dr. M.G.R. University, Chennai, Tamil Nadu, India. Dec. 20-22, 2007 
[7] Juan C. Gomez Morcos ,Rio Cuarto, USA, "Contactor immunity related to voltage sags", 19th International Conference on Electricity Distribution Vienna, 21-24 May 2007.

\section{Biography}

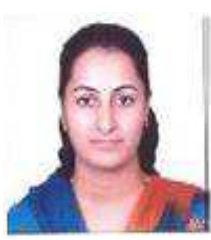

Sonali Mayuresh Akolkar received her B.E. (Electrical) from Nagpur University, Maharashtra (India) in 1997 and M.E. (Electrical-Control Systems) in 2009 from Electrical Engg. Dept.,of K.K. Wagh I. E. E. \& $\mathrm{R}$, Nashik (Maharashtra), India.
[8] Hung, Chih-Yu, Chi, Chieh-Tsung, "A New Compensation Strategy for an AC Contactor under voltage-Sag Events", 978-1-4244-6506-4/10/\$26.00, 2010 IEEE.

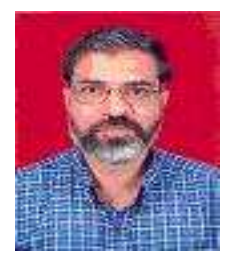

Bansidhar Eknath Kushare received B.E. (Electrical), M.E. (Electrical) form Marathwada University and University of Pune in 1989 and 1992 and Ph.D. degree from University of Pune, in 2007 respectively. Currently he is Professor and Head of Electrical Engg. Dept., K. K. Wagh I. E. E. \& R, Nashik (Maharashtra), India. His research area includes power quality and he is a certified Energy Auditor of BEE. He is Power Quality, Electrical \& Energy Management consultant to many national and multi national industries. 